\title{
Chronic Appendicitis: Diagnostic Dilemma in Female Patient for Recurrent Lower Abdominal Pain
}

\author{
Nahar K ${ }^{1}$, Hossain SMA ${ }^{2}$, Khatun $A^{3}$
}

Conflict of Interest: None Received: $15-10-2017$

Accepted: 06-03-2018 www.banglajol.info/index.php/JSSMC

\section{Key Words:}

Chronic appendicitis, Recurrent lower abdominal pain, Appendectomy.

\begin{abstract}
Background: Many female patients presented to gynecologist with chronic lower abdominal pain, suspecting chronic PID or UTI, but found no improvement inspite of repeated treatment. It remains as diagnostic dilemma for gynaecologist. Proper diagnosis ultimately shows that it is a case of chronic appendicitis. The main purpose of this study was to evaluate the clinical feature of chronic appendicitis and its correlation with operative and histological findings \& to create alertness of physicians and prevention of later complication.
\end{abstract}

Methods: This cross-sectional study was carried out in female patients in private practice from January 2014 to December 2017. All patientswho complained frequent attacks of pain in their right lower abdomen were included in our study. The patient's history, clinical and lab findings were closely evaluated. All the patients underwent appendectomy and all their appendices were histopathologically examined. Chronic appendicitis was ruled in with a positive pathology report confirming chronic inflammation. All the patients referred for their follow-up visits in a period of one year.

Results: A total100 female patients were studied.66\% patient were in age group 26 to 35 years. $87 \%$ patients were multiparous. Duration of pain varied from 2 weeks to 2.5 years. Histopathology report confirmed chronic appendicitis in $96 \%$ cases. From them $94 \%$ cases expressed complete relief of pain following removal in the follow-up visit.

Conclusion: Chronic appendicitis seems to be a cause of recurrent lower abdominal pain. The disease is easily cured by appendectomy.

[J Shaheed Suhrawardy Med Coll 2018; 10(1): 59-61] DOI: http://dx.doi.org/10.3329/jssmc.v10i1.38906

\section{Introduction}

The diagnosis of classical acute appendicitis is generally straight forward, often manifesting as several hours of periumbilical pain localizing to the right iliac fossa with associated anorexia, abdominal guarding \& low grade pyrexia. $^{1}$

Atypical \& chronic presentations are less common but are believed to result from partial \& transient obstruction of the appendix. ${ }^{2}$ The incidence of chronic appendicitis is

1. Dr. Khairun Nahar, Associate Professor(Obs\& Gynae), Shaheed Suhrawardy Medical College, Sher-e-Bangla Nagar, Dhaka

2. Dr. S.M. Amjad Hossain, Former Professor (Surgery), Shaheed Suhrawardy Medical College, Sher-e-Bangla Nagar, Dhaka

3. Dr. Ashia Khatun, Associate Professor (Obs\& Gynae), Shaheed Suhrawardy Medical College, Sher-e-Bangla Nagar, Dhaka.

Correspondence to: Dr. Khairun Nahar, Associate Professor(Obs\& Gynae), Shaheed Suhrawardy Medical College, Sher-e-Bangla Nagar, Dhaka estimated at $1.5 \%$ of all cases. ${ }^{3}$ Although once controversial, ${ }^{4}$ recurrent $\&$ chronic appendiceal disease is now well document in medical literature ${ }^{5}$ This entity poses a diagnostic dilemma for clinicians because patients generally do not present with typical appendicitis symptoms. Often time these patients are misdiagnosed particularly sexually active females or those partially treated with antibiotic for other conditions. Female patients are usually diagnosed as PID or UTI, Missing the diagnosis can have serious consequence as riskof abscess formation and infertility. ${ }^{5}$ Some authors have proposed the following criteria for chronic appendicitis :Persistence of symptoms for more than two weeks, confirmation of chronic appendiceal inflammation on pathologic examination and relief of symptoms following appendicectomy. 7,8 Histopathological findings of chronic appendicitis include an inflammatory infiltrate consisting of lymphocytes, histiocytes and eosinophils besides associated fibrosis 
of the appendiceal wall. ${ }^{9}$ The pathophysiology of chronic appendicitis is thought to represent partial or recurrent obstruction of the appendiceal lumen by fecoliths, lymphoid hyperplasia, tumours and foreign bodies. Luminal secretions accumulate with progressive dilatation of the appendix until intraluminal pressure over comes the obstruction resulting in extrusion of the appendices contents and subsequent complete or partial relief of symptoms. ${ }^{7}$ In this study we evaluate a group of patients who were suffering from frequent attack of pain and discomfort in their right lower abdomen.

\section{Materials and Methods}

This was a prospective cross-sectional study. Total 100 cases were taken from January 2014 to December 2017. History taking in all patients were followed by a thorough physical examination. Patients with right lower abdominal pain for more than 2 weeks and $\mathrm{H} / \mathrm{O}$ repeated visit to gynecologist for treatment wereincluded in this study. Cases in whom abdominal pain could be attributed to a previous abdominal surgery or an underling disease such as hepatitis or parasitic infections were excluded from the study. On physical examination all the patients showed tenderness in Mc Burney's point on deep palpation. $\mathrm{P} / \mathrm{V}$ examination also done to exclude any gynecological problem. All patients were re-evaluated again by expert surgeon. All the patients underwent appendectomy by surgeon later on. Experienced pathologist carefully examined all appendix specimens for signs of chronic inflammation.

In one year follow up, the cases were observed but no recurrent pain was found. The collected data were analyzed via statistical measures.

\section{Result}

A total 100 female patients were studied.66\% patient were in age group 26 to 35 years(Table-I). $87 \%$ patients were multiparous (Table-II). Duration of pain varied from 2 weeks to 2.5 years (Table-III). $70 \%$ patients had dyspepsia(TableIV).Laparoscopic removal of appendix done in $82 \%$ (TableV).Histopathology report confirmed chronic appendicitis in $96 \%$ cases (Table-VII). From them $94 \%$ cases expressed complete relief of pain following removal in the follow-up visit (Table-VIII).

\section{Table-I}

\begin{tabular}{lcc} 
Age of patient & No. of cases (n-100) & Percentage \\
\hline$<15$ years & 02 & $2 \%$ \\
$16-25$ years & 09 & $9 \%$ \\
$26-35$ years & 66 & $66 \%$ \\
$36-40$ years & 23 & $23 \%$ \\
\hline
\end{tabular}

Table-II

\begin{tabular}{lcc} 
Parity & No of cases & Percentage \\
\hline Nulliparous & 13 & $13 \%$ \\
Multiparous & 87 & $87 \%$ \\
\hline
\end{tabular}

Table-III

\begin{tabular}{lcc} 
Duration of pain & No of cases & Percentage \\
\hline 2wks- 8 wks & 44 & $44 \%$ \\
9wks- 6month & 22 & $22 \%$ \\
6month-2.5 years & 34 & $34 \%$ \\
\hline
\end{tabular}

Table-IV

\begin{tabular}{lcc} 
Other clinical symptoms & No of cases & Percentage \\
\hline Dyspepsia & 70 & $70 \%$ \\
P/V discharge & 10 & $10 \%$ \\
Dysparunia & 12 & $12 \%$ \\
Backache & 07 & $7 \%$ \\
Infertility & 05 & $5 \%$ \\
\hline
\end{tabular}

Table-V

\begin{tabular}{lcc} 
Operative Procedure & No of cases & Percentage \\
\hline Laparoscopy & 82 & $82 \%$ \\
Laparotomy & 18 & $18 \%$ \\
\hline
\end{tabular}

Table-VI

\begin{tabular}{lcc} 
Operative Findings & No of cases & Percentage \\
\hline $\begin{array}{l}\text { Fibroses appendix withs } \\
\text { unken tips with adhesion }\end{array}$ & 89 & $89 \%$ \\
$\begin{array}{l}\text { to surrounding structure } \\
\text { Only Fibrosis }\end{array}$ & 11 & $11 \%$ \\
\hline
\end{tabular}

Table-VII

\begin{tabular}{lcc} 
Histopathological & No of cases & Percentage \\
\hline findings & & \\
$\begin{array}{l}\text { Features of chronic } \\
\text { inflammation }\end{array}$ & 96 & $96 \%$ \\
No specific evidence & 04 & $4 \%$ \\
\hline
\end{tabular}


Table-VIII

\begin{tabular}{lcc}
$\begin{array}{l}\text { Improvement of } \\
\text { symptoms afteroperation }\end{array}$ & No of cases & Percentage \\
\hline Complete relieve of pain & 94 & $94 \%$ \\
Pain $>6$ months & 06 & $6 \%$ \\
\hline
\end{tabular}

\section{Discussion}

This chronic lower abdominal pain is a common complaints among women and accounts for 20-30\% of Gynecologic consultations. ${ }^{10}$ Chronic appendicitispatients present with a variety of complaints mostly lower abdominal pain mimics acute appendicitis but have a more prolonged duration. ${ }^{11}$ To confirm the diagnosis of chronic appendicitis surgeons not only require a pathology proof but series of other criteria as well. A group of physicians think that repeated episodes of abdominal pain make a diagnosis of appendicitis unlikely. ${ }^{12}$ Our study besides some similar surveys shed more light on this controversial topic. Our patients had experienced several attacks of pain in their right lower abdomen for at least more than two weeks which had taken them to physicians /gynecologist each time.

Demographic analysis showed a significantly higher prevalence in women in 26-35 years (66\%) It corresponds with similar study where prevalence in women is $62.5 \% 5$

In this study, chronic appendicitis was found more in multiparous women ( $87 \%$ ) possibly delivery process may invite infective organisms. Pain varied in duration from at least two weeks to 2.5 years. ${ }^{5}$ Present study findings correlates with it. Dyspepsia is a feature of chronic appendicitis, ${ }^{1}$ which was present in $70 \%$ cases here.

Vaginal discharge was found in 10\%, dyspareunia in 12\%, backache in $7 \%$ and in fertility was found in $5 \%$ of cases. These findings may be related with pelvic \&retrocaecal location of appendix. Chronic appendicitis presented as low back pain in one study. ${ }^{7}$

Laparoscopic removal of appendix was done in $82 \%$ cases, laparotomy done in $18 \%$ cases. Among these $89 \%$ shows fibrosis\& shrunken tip of appendix with adhesion to surrounding structure. Rest $11 \%$ only fibrosis seen.

Histopathological report of $96 \%$ patient here shows chronic inflammation. In a similar study up to $89 \%$ of appendix specimen in such patients were abnormal. ${ }^{5}$
Complete relieve of pain occurs in $94 \%$ cases in this study which almost correlates with another study where $93.8 \%$ patient revealed compete relief. ${ }^{5}$

\section{Conclusion}

Chronic appendicitis should be assumed as an independent diagnostic entity while approaching to recurrent pain in lower abdomen in female patient. As there is high rate of recovery following appendectomy, it should beconsider as an effective treatment especially when all other differential diagnosis have already been ruled out.

\section{References}

1. Norman S. Williams, Christopher J.K, Bulstrode\& P. Ronan O'connell; Short practice of Surgery, 2008; $25^{\text {th }}$ edition; P1206-1208\& 1217

2. Von Winter, J.T and Beyer, D.A, Chronic appendicitis diagnosed preoperatively as an ovarian dermoid, J PediatorAdolescGynaecol, 2004; 17; 403-406

3. Hawes, A.S and Whalen, G.H. Recurrent and chronic appendicitis; the other inflammatory conditions of the appendix. Am Surg. 1994; 60 : 217.

4. Crabbe MM, Norwood SH, Robertson HD, Silva JS. Recurrent and chronic appendicitis. Surg GynaecolObstet1986 : 163(I); 11-13

5. M. Safaei MD, L.Moeinei MD, M Rasti Md. Recurrent Abdominal pain and chronic appendicitis. Journal of Reseach in Medical Science 2004; 1; 11-14.

6. Muller B.A. Daling J.R, Moore D.E et all. Appendectomy and the risk of tubal infertility N Engl J Med. 1986; 315; 1506

7. Drezner JA, Harman KG. Chronic appendicitis presenting as low back pain in a recreational athlete. Clin J sport Med recreational athlete. Clin J sport Medi 2002; 12 (3); 194186

8. Ellis H. Nathanson LK. Appendix and appendectomy In: Maingot's abdominal operations $10^{\text {th }}$ edition. July, 1997; 1222

9. Lewis FR, Holcroft JW, Boey J et all. Appendicitis; a critical review of diagnosis and treatment in 1000 cases; Arch surg, $1975 ; 110 ; 677-684$

10. Reiter, R.C A profile of women with chronic pelvic pain. Clin. Obstet. Gynaecof, 1990, 33; 130-136.

11. Minerva chir. Recurrent abdominal pain and chronic appendicitis 2000; 55 (1-2); 39-44.

12. Fayes JA, Toy NJ, Flanagan TM. The Appendix as the cause of chronic lower abdominal pain Am Jobstetgynalcol 1995; 172 (1), 122-123

13. Stenchever M. Significant symptoms and signs in different age groups in Herbest A. Comprehensive Gynecology. $2^{\text {nd }}$ edition. St louis Mosby-Yearbook co. 1992, 161-183

14. Shah SS. Gaffney RR. Dykes TM, GoidsteinJP chronic appendicitis; An often for gotten cause of recurrent abdominal pain. Am J Med. 2013, Jan 